Farm animal welfare - who writes the rules?

Occasional Publication No. 23 - British Society of Animal Science 1999

edited by A. J. F. Russel, C. A. Morgan, C. J. Savory, M. C. Appleby and T. L. J. Lawrence

\title{
The effect of cow-calf separation in dairy cattle on animal behaviour
}

\author{
J. K. Margerison ${ }^{1}$, C. J. C. Phillips ${ }^{2}$ and T. R. Preston ${ }^{3}$ \\ ${ }^{1}$ Department of Agriculture and Food Studies, Seale-Hayne Faculty, University of Plymouth, Newton Abbot, Devon \\ TQ12 6NQ \\ ${ }^{2}$ Department of Clinical Veterinary Medicine, University of Cambridge, Madingley Road, Cambridge CB3 OES \\ ${ }^{3}$ Department of Agriculture and Forestry, University of Ho Chi Min, Ho Chi Min City, Vietnam
}

\section{Introduction}

The abrupt separation of cows and calves has been found to affect both cow and calf behaviour (Hopster et al., 1995). This abrupt separation is typical in artificial calf rearing systems which are common practice in the majority of beef and dairy production programmes. The artificial rearing of calves is characterized by individual penning, which facilitates accurate measurement of food intakes but limits calf contact. Cross-suckling behaviour has been found to occur frequently in artificially reared calves (Wood et al., 1967; Lalande et al., 1979) and individually penned calves have been found to perform stereotypic behaviours which are generally oral in nature. In contrast, calf rearing in developing countires is dominated by the use of suckling systems. The dairy production systems limit suckling to facilitate milk removal, which allows the calf and the cow to have continued but limited contact. In these systems cows have been found to give greater milk yields and calves reared by limited suckling seem to have greater milk conversion efficiencies (Ugarte and Preston, 1972; Gaya et al., 1978; Knowles and Edwards, 1983) and lower mortality rates (Ugarte, 1989; Alvarez et al., 1980) compared with calves reared artificially. However, the effect of abrupt separation of the cow and calf has been found to be relatively short lived with cows and calves showing increased cortisol levels and 'stress' for up to 6 to $8 \mathrm{~h}$ following separation (Hopster et al., 1995). This may indicate that cows which are continually separated from their calves may be subjected to repeated periods of 'stress' each time the cow and calf are separated. The objective of this experiment was to compare the effect on cow and calf behaviour of abrupt cow-calf separation and continuous limited contact between cows and their own calf or a foster calf.

\section{Material and methods}

The experiment was completed in Colombia with the co-operation of a non-government organizations Centro Inter-institucional para la Producción de
Agropecuaria en el Valle del Rio Cauca (CIPAV) and a commercial dairy farm, Hacienda Lucerna. At 4 days post partum 36 multiparous dairy cows were allocated to one of three treatments, where they remained for the following lactation (up to 305 days). The treatments used were: a non-suckling treatment (NS), where the cow and the calf were separated at 4 days post partum and the calves were reared artificially and separately from the dam and two limited suckling treatments where the cows were sucked for $15 \mathrm{~min}$ following mechanical milking. In the first treatment, 12 cows were sucked by their own calf (SM) and in the second experiment, 12 cows were sucked by a foster calf (SF). The calves were reared in their treatment groups and all the experimental cows were grazed together throughout the experiment. The behaviour study was conducted over $24 \mathrm{~h}$ at 30 -day intervals, equivalent to three observation periods during the first 100 days of lactation or age. Behavioural observation periods began after morning milking and continued until the same time the following day. During these periods each animal was observed once every $5 \mathrm{~min}$ until dusk and then every 15 min until dawn. The cows and calves were observed on the same days. During the observation periods the times cows spent in various behaviours were recorded. A count of the number of acts of aggression were recorded, using 15 -min recording periods. In calves the times spent lying, grazing, sucking, feeding on concentrate and standing were recorded. The incidence of walking, non-nutritive cross-sucking, allo-grooming, grooming others and agonistic behaviour were recorded, using 15-min recording periods during which the number of actual events were recorded. The duration of sucking and the incidence of cross-sucking was recorded by observing calves for $6 \mathrm{~s}$ every minute during and for $20 \mathrm{~min}$ following the ingestion of milk. Cross-sucking was defined as a calf performing sucking movements while having some part of another calf's body in its mouth. During this crosssucking, new sucking events were recorded when: a calf stopped sucking one calf and sucked another calf; the calf changed to suck another part of the 
Table 1 Behaviour in suckled and non-suckled cows (min or incidence per $24 h$ )

\begin{tabular}{lcccc}
\hline \hline Activity & $\begin{array}{c}\text { Non- } \\
\text { suckled }\end{array}$ & $\begin{array}{c}\text { Suckled } \\
\text { (Foster) }\end{array}$ & $\begin{array}{c}\text { Suckled } \\
\text { (Maternal) }\end{array}$ & s.e.d.t \\
\hline Grazing & 348 & 360 & 348 & $25 \cdot 5$ \\
Lying & 150 & 145 & 148 & $18 \cdot 0$ \\
Lying ruminating & 440 & 437 & 442 & $24 \cdot 1$ \\
Standing ruminating & 120 & 116 & 119 & $10 \cdot 1$ \\
Total ruminating & 550 & 553 & 561 & $30 \cdot 2$ \\
Feeding & 59 & 59 & 61 & $25 \cdot 5$ \\
Walking & 111 & 105 & 109 & $12 \cdot 0$ \\
Standing & 212 & 218 & 213 & $9 \cdot 6$ \\
Total & 1440 & 1440 & 1440 & - \\
Aggression & $2 \cdot 1$ & $1 \cdot 9$ & $1 \cdot 7$ & 0.08 \\
\hline \hline
\end{tabular}

+ All differences not statistically significant $(P>0.05)$.

body; or the calf stopped to perform another behaviour and then resumed sucking the same calf and body part. During cross-sucking events, the body area which was sucked and the calf performing the sucking and being sucked were recorded.

All the data were analysed using the Minitab software package. The behaviour data which were not normally distributed was transformed by adding 0.5 to each observation and then were analysed as with normally distributed data. The data were analysed using analysis of variance (ANOVA) with the generalized linear model (GLM) and a significant effect was determined from the ' $P$ ' value in the ANOVA table for three treatments, following which the treatments were paired and compared by Tukey's method for equal observations.

\section{Results}

The times spent in various behavioural activities during three 24-h periods by the cows are presented in Table 1. Behaviour was similar in all the treatment groups, with suckling treatment having no significant effect on grazing, lying, feeding, walking, standing or ruminating (either standing and lying) time in the long term.

The time spent and the incidence of various behavioural activities during $24 \mathrm{~h}$ by the calves are presented in Table 2 . In all the treatment groups, the time spent lying and standing were similar. However, the time spent eating concentrate was significantly greater $(P<0 \cdot 05)$ in calves reared artificially, compared with restrictedly suckled calves. The frequency of cross-sucking was greater in calves reared artificially, $(P<0.05)$ compared with calves which were restricted suckled. The number of incidents of walking, grooming and performing agonistic behaviour was similar in all the treatments groups.

During the experiment, a total of 96 instances of cross-sucking were recorded. In artificially reared calves the frequency of cross-sucking was greatest directly following the ingestion of milk and the frequency reduced slowly over the following $15 \mathrm{~min}$, falling to negligible levels at around $12 \mathrm{~min}$ post feeding. In restrictedly suckled calves, the incidence of cross-sucking was significantly lower and the incidents occurred only after calves had been sucking the cows for $12 \mathrm{~min}$.

\section{Discussion}

In this experiment the long-term behaviour in calves was similar irrespective of whether they had been sucked by calves with no significant effect of suckling treatment on grazing, lying, feeding, walking, standing or ruminating (either standing and lying) time. However, it has been found that cows and calves show increased cortisol levels and 'stress' in the short term, within 6 to $8 \mathrm{~h}$ following

Table 2 Behaviour in suckled and non-suckled calves (min or incidence per $24 \mathrm{~h}$ )

\begin{tabular}{|c|c|c|c|c|c|}
\hline Activity & Non-suckled & Suckled (Foster) & Suckled (maternal) & s.e.d. & $P$ \\
\hline \multicolumn{6}{|l|}{ Time spent (min/day) } \\
\hline Lying & 970 & 968 & 965 & $110 \cdot 0$ & \\
\hline Standing & 325 & 342 & 336 & $45 \cdot 5$ & \\
\hline Feeding (concentrate) & 70 & 33 & 39 & $13 \cdot 5$ & * \\
\hline Grazing & 10 & 13 & 14 & $7 \cdot 1$ & \\
\hline Suckling & 25 & 28 & 29 & $5 \cdot 1$ & \\
\hline Total & 1400 & 1384 & 1383 & - & \\
\hline \multicolumn{6}{|l|}{ Incidents (no. per $24 \mathrm{~h}$ ) } \\
\hline Walking & $26 \cdot 4$ & $30 \cdot 4$ & $32 \cdot 0$ & $6 \cdot 5$ & \\
\hline Grooming (self) & $14 \cdot 7$ & $18 \cdot 2$ & $19 \cdot 1$ & $4 \cdot 1$ & \\
\hline Grooming (other) & $2 \cdot 3$ & $5 \cdot 1$ & 3.5 & $1 \cdot 7$ & \\
\hline Agonistic & $11 \cdot 1$ & $10 \cdot 4$ & 9.8 & $2 \cdot 56$ & \\
\hline Cross-suckling & 1.80 & 0.52 & $0 \cdot 14$ & $0 \cdot 231$ & * \\
\hline
\end{tabular}


separation (Hopster et al., 1995) and these responses were observed over a longer period. It has been found also that cows respond to the calf when it is placed in an adjoining paddock (Hudson and Mullford, 1977). The cows in this experiment were grazed at least $300 \mathrm{~m}$ away from where the calves were housed and did not show any signs of response. The cows used in this experiment were multiparous and Hopster et al. (1995) found that multiparous cows only respond mildly immediately following cow-calf separation. The results indicated that the continuous limited suckling and repeated cow-calf separation had no significant effect on cow behaviour. The incidence of cross-sucking was found to be significantly greater in artificially reared calves compared with limited suckled calves. This crosssucking has been found to occur in artificially reared calves (Wood et al., 1967; Lalande et al., 1979) particularly those reared in groups. In contrast, the incidence of cross-sucking in the limited suckled calves was negligible. In the artificially reared calves the frequency was found to be greatest following milk ingestion, which is similar to previous work with artificially reared calves (Hammel et al., 1988; Passillé et al., 1992; Lidfors, 1993). The ingestion of milk has been found to increase the motivational state (Toates, 1986) of the calf to perform sucking behaviour. Also the ingestion of only small quantities of milk has been found sufficient to stimulate cross-sucking (Brake et al., 1982). The artificially reared calves spent significantly less time consuming milk, which left them with a high sucking motivation. As a consequence the incidence of crosssucking was greater in calves reared artificially. In contrast, limited suckled calves spent longer sucking and consequently would return to a pen with a low motivational state which would result in a low incidence of cross-sucking.

\section{References}

Alvarez, F. J., Saucedo, G., Arriaga, A. and Preston, T. R. 1980. Effect on milk production and calf performance of milking crossbred European/Zebu cattle in the absence or presence of the calf, and of rearing their calves artificially. Tropical Animal Production 5: 25-37.
Brake, S. C., Sager, D. J., Sullivan, R. and Hofer, M. 1982. The rôle of intra-oral and gastrointestinal ones in the control of suckling and milk consumption in rat pups. Development Psychobiology 15: 529-541.

Gaya, H., Hulman, B. and Preston, T. R. 1978. Effect of two methods of restricted suckling on performance of cows and on the growth rate of calves. Tropical Animal Production 3: 118-124.

Hopster, H., Connell, J. M. and Blokhuis, H. 1995. Acute effects of cow-calf separation on heart rate, plasma cortisol and behaviour in multiparous dairy cows. Applied Animal Behaviour Science 44: 1-8.

Hammell, K. L., Metz, J. H. M. and Mekking, P. 1988. Suckling behaviour of dairy calves fed milk ad libitum by bucket or teat. Applied Animal Behaviour Science 20: 275-285.

Hudson, S. and Mullford, M. M. 1977. Investigation of maternal bonding in cattle. Applied Animal Ethology 3: 271-276.

Knowles, R. T. and Edwards, M. D. 1983. A comparison of the effects of restricted suckling and artificial calf rearing systems on dam and calf performance. Malaysian Agricultural Journal 54: 1-9.

Lalande, G., Beauchemin, K. and Fahmy, M. M. 1979. A note on the performance of Holstein Friesian veal calves raised to weaning individually or in groups. Annals of Zootechnia 28: 235-238.

Passillé, A. M. B., Metz, H. M., Mekking, P. and Wiepkema, P. R. 1992. Does drinking milk stimulate suckling in young calves? Applied Animal Behaviour Science 34: 23-36.

Toates, F. 1986. Motivational systems. Cambridge University Press, Cambridge.

Ugarte, J. 1989. Restricted suckling in dual purpose systems. Feeding dairy cows in the tropics. Proceedings of the FAO expert consultation. Bangkok, Thailand 7-11 July 1989, pp. 199-207. Food and Agriculture Organization, Rome.

Ugarte, J. and Preston, T. R. 1972b. [Milk production and calf growth as affected by the length of the interval between milking and suckling.] Revista Cubana de Ciencia de Agricultura 6: 331-336.

Wood, P. D. P., Smith, G. F. and Lisle, M. F. 1967. A survey of inter-suckling in dairy herds in England and Wales. Veterinary Record 81: 396-398. 